\title{
Individual differences in chimpanzee reconciliation relate to social switching behaviour
}

\author{
Christine E. Webb ${ }^{\mathrm{a}, \mathrm{b}, *}$, Becca Franks ${ }^{\mathrm{a}}$, Teresa Romero ${ }^{\mathrm{b}, \mathrm{c}}$, E. Tory Higgins ${ }^{\mathrm{a}}$, \\ Frans B. M. de Waal ${ }^{\text {b }}$ \\ a Department of Psychology, Columbia University, New York, NY, U.S.A. \\ ${ }^{\mathrm{b}}$ Living Links, Yerkes National Primate Research Center, Emory University, Atlanta, GA, U.S.A. \\ ${ }^{\mathrm{c}}$ Department of Cognitive and Behavioral Science, The University of Tokyo, Tokyo, Japan
}

\section{A R T I C L E I N F O}

\section{Article history:}

Received 17 October 2013

Initial acceptance 18 November 2013

Final acceptance 3 January 2014

Published online

MS. number: A13-00871R

\section{Keywords:}

behavioural switching

chimpanzee

individual differences

Pan troglodytes

personality

reconciliation

regulatory mode theory
In recent years, the presence of stable individual variation in animal behaviour has been corroborated by studies across a wide variety of taxa and research disciplines. Reconciliation, or postconflict affiliation between former opponents, is a behavioural domain in which individual differences have not been systematically studied. Using a long-term data set comprising over 2000 conflict and postconflict observations in two groups of outdoor-housed chimpanzees, Pan troglodytes, we provide evidence for stable individual variation in reconciliation and test several hypotheses on how this postconflict mechanism relates to social switching behaviour. Results of generalized multilevel models revealed that individual differences remained a substantial source of variation in reconciliation after controlling for a number of situational variables (e.g. the nature of the relationship between opponents) shown by previous research to influence its occurrence. We further demonstrated a positive association between an individual's conciliatory tendency and three separate indices of social switching behaviour, proposing that individual differences in reconciliation may reflect a more fundamental motivation to switch between different social states. In addition to a discussion of potential motivational underpinnings, we provide an impetus for future work to consider how reconciliation relates to the broader constructs and themes identified within animal personality research. To the extent that individual differences in other aspects of conflict and postconflict repertoires exhibit temporal and cross-situational consistency, they too should inform our understanding of animal personalities. Delineating how these and other dimensions of sociality are in part driven by stable individual variation not only has implications for how social interactions themselves unfold, but ultimately for the fitness of the individuals therein.

(c) 2014 The Association for the Study of Animal Behaviour. Published by Elsevier Ltd. All rights reserved.
Stable individual differences in animal behaviour, often termed 'animal personalities', are the focus of a large and growing body of recent research (Bell, Hankison, \& Laskowski, 2009; Dingemanse \& Réale, 2005; Sih, Bell, \& Johnson, 2004; Sih, Bell, Johnson, \& Ziemba, 2004). Such differences are manifest in evolutionarily meaningful patterns such as activity, mating, feeding, predation and sociality, ultimately translating into important fitness consequences for the individual (Sih, Bell, Johnson, \& Ziemba, 2004). Conflict and postconflict repertoires are a social domain in which individual differences remain relatively unexplored. Reconciliation, first defined by de Waal and van Roosmalen (1979) as interopponent postconflict affiliation, represents an evolved strategy to preserve the benefits (and minimize the costs) of conflict-inherent group life. Initially

\footnotetext{
* Correspondence: C. E. Webb, Department of Psychology, Columbia University, 406 Schermerhorn Hall, 1190 Amsterdam Avenue, New York, NY 10027, U.S.A

E-mail address: cw2472@columbia.edu (C. E. Webb).
}

documented in chimpanzees, reconciliation has since been reported in over 30 primate species (reviewed in Aureli, Cords, \& van Schaik, 2002) and an increasing number of nonprimates (reviewed in Schino, 2000), most recently in canids (Cools, Van Hout, \& Nelissen, 2008; Cordoni \& Palagi, 2008) and corvids (Fraser \& Bugnyar, 2011). Two central assumptions of reconciliation are that it involves a switch between opposing motivational states (i.e. from hostility and fear to a positive inclination) and that this motivational shift serves to repair social relationships (de Waal, 2000). Accordingly, the valuable relationships hypothesis (VRH; de Waal \& Aureli, 1997) predicts that reconciliation will be more frequent following conflicts between opponents who derive higher fitness benefits from their relationship (Kappeler \& van Schaik, 1992), presuming conflicts actually disrupt such relationships (Aureli et al., 2002). The VRH been substantiated by both observational (reviewed in Watts, 2006) and experimental research (Cords \& Thurnheer, 1993) across many nonhuman primate species, recently gaining further traction in the human literature (e.g. 
McCullough, Luna, Berry, Tabak, \& Bono, 2010). But while its proponents have correctly pointed out that value in a given relationship is not always symmetric (i.e. equivalent for both partners; e.g. Cords \& Aureli, 2000), the premise has not yet led to a systematic investigation of whether individuals are differently motivated to resolve conflict.

Recent work by Seyfarth, Silk, and Cheney (2012) demonstrates that other aspects of primate sociality are influenced by stable individual differences, in turn impacting an animal's fitness. In a principal component analysis of female baboon behaviour, researchers identified several personality styles to be associated with multiple measures of reproductive success. These individual dimensions influenced the strength and stability of social bonds (critical to fitness in this species: Silk et al., 2010), accounting for variance beyond that explained by kinship and dominance rank. Similarly, by studying how other social processes (for instance, reconciliation) are driven in part by stable individual variation, we stand to gain a more complete understanding of the adaptive consequences of behaviour. In addition to social personality traits (see also Koski, 2011), primate personality research has adopted diverse psychological approaches ranging from bold-shy continua (Wilson, Clark, Coleman, \& Dearstyne, 1994) to five-factor models (reviewed in Freeman \& Gosling, 2010) to the use of more recent motivational frameworks such as promotion and prevention orientations (Franks et al., 2013). The primary goal of the present study was to identify whether there are stable individual differences in reconciliation, controlling for other social variables known to influence its occurrence. If stable individual variation in reconciliation is indeed present, subsequent research might then consider including conciliatory tendency as a component of broader animal personality. That such variation has not been the subject of past research may be because reconciliation is often viewed as an interindividual, as opposed to intraindividual, phenomenon.

While social psychology has a longer tradition of recognizing that individual-level variables affect interrelational processes (Leary \& Hoyle, 2009), even here relatively little specific consideration has been given to how individual differences shape reconciliation. The human literature typically emphasizes forgiveness, most commonly defined as the set of postconflict motivational changes whereby an individual becomes decreasingly motivated by negative inclinations and increasingly motivated by positive conciliation (McCullough, Worthington, \& Rachal, 1997). Given how central an assumption this motivational shift between states is for reconciliation (de Waal, 2000), it could be that a more basic and general motivation for change underlies this behaviour. In particular, regulatory mode theory (RMT; Higgins, Kruglanski, \& Pierro, 2003; Kruglanski et al., 2000) describes individual variation in locomotion motivation, a tendency for movement (and fast initiation of change) from state to state. As such, the secondary goal of the present study was to test whether RMT can help explain how individual variation in reconciliation may relate to more fundamental individual differences in motivation, namely the motivation to switch between different social states. It bears repeating that we refer to locomotion not as the biomechanics of animal movement, but as a motivational style, heretofore demonstrated in humans across a wide range of research domains (Higgins, 2012). Preliminary evidence reveals that people with strong locomotion motivation have higher and faster conciliatory tendencies following interpersonal conflicts (Webb, 2011). Indeed, recent work has extended psychological theories developed in relation to human personality to stable individual variation in animal behaviour (e.g. Uher, Asendorpf, \& Call, 2008). Franks and colleagues (Franks, Higgins, \& Champagne, 2012; Franks et al., 2013) have recently validated the use of similar motivational models (Higgins, 1997) in the study of personality differences across species.
We used a long-term data set of chimpanzee conflict and postconflict behaviour (1) to establish whether individual differences in reconciliation were present and, importantly, stable across time and situations (i.e. as a possible constituent of broader animal personality) and (2) to examine the relation between these differences and three behavioural measures of locomotion motivation (hereafter, social switching behaviour). Our first prediction was that stable individual variation in postconflict behaviour would be present when controlling for a number of other variables shown by previous studies to influence reconciliation (such as kinship, dominance and affiliation level). RMT provided a conceptual framework for our second prediction that individuals with higher conciliatory tendencies would exhibit more social switching behaviour. Overall, both the long-term nature and large sample size of the current data set make it a particularly good candidate for exploring these patterns and the stability of individual differences over time, especially given the high number of observations on spontaneously occurring behaviours. Although a number of past studies have reported different individual reconciliation rates (e.g. Preuschoft, Wang, Aureli, \& de Waal, 2002), to our knowledge, ours is the first quantitative overview of that variation and an initial step in determining how it relates to a more basic tendency to switch between states.

\section{METHODS}

\section{Subjects and Housing}

Subjects were 31 adult and adolescent chimpanzees, socially housed at the Field Station of the Yerkes National Primate Research Center in Atlanta, Georgia, U.S.A. Two separate groups (FS1 and FS2) had access to indoor areas and large outdoor compounds $\left(750 \mathrm{~m}^{2}\right.$ and $520 \mathrm{~m}^{2}$, respectively) equipped with visual barriers, a variety of climbing structures and enrichment toys. Food and water were available ad libitum.

Group demographic compositions varied throughout the study period as a result of births, deaths and removals. At any given time, both groups comprised multiple adult males and at least twice as many adult females. Our analyses were limited to conflicts in which at least one of the opponents was $8+$ years old, resulting in nine male subjects and 22 female subjects. Adults/adolescents had to be involved in more than 12 observed conflicts throughout the study period to be included as a subject. A more detailed description of the study subjects can be found in Romero and de Waal (2010, Table 2).

The Yerkes National Primate Research Center is accredited by the American Association for the Accreditation of Laboratory Animal Care. All procedures were approved by the Institutional Animal Care and Use Committee of Emory University and were conducted in accordance with the ASAB/ABS's Guidelines for the treatment of animals in behavioural research and teaching.

\section{Observations}

The data analysed in the present study were collected between 1992 and 2000 for FS1 and between 1994 and 2000 for FS2. Throughout that time, controlled observation sessions were conducted approximately once per week in both study groups by the same trained research technician, Mike Seres (see de Waal, 1989 for details). During these 90 min sessions, all occurrences of agonistic interactions (defined by at least one the following behaviours: tug, brusque rush, trample, bite, grunt-bark, shrill-bark, flight, crouch, shrink/flinch or bared-teeth scream; van Hooff, 1974; de Waal \& van Hooff, 1981) were recorded, as well as affiliative interactions (kiss, embrace, groom, touch, finger/hand in mouth, play and mount). 
Additionally, observation sessions included scan samples (in 5 min intervals through 1993 and 10 min intervals in subsequent years) of state behaviours (e.g. contact sitting).

As the sessions were not designed to study postconflict interactions directly, formal postconflict (PC) and matched-control (MC) observations were not conducted. However, because the recordings were continuous, the behaviour of opponents following agonistic interactions represents PC data (de Waal \& Yoshihara, 1983). For each conflict, the identities of the initial aggressor and recipient of aggression were noted, as was the conflict's intensity (i.e. with or without physical contact). Polyadic conflicts (i.e. those involving more than 2 individuals) were divided into dyadic components (de Waal \& van Hooff, 1981).

Following the standard PC-MC procedure (de Waal \& Yoshihara, 1983), former opponents were observed for a 10 min PC period, where all subsequent affiliative and agonistic interactions, as well as the initiator, recipient and timing of those interactions, were recorded. Each PC was paired with an MC of the same duration, recorded on the nearest observation day (always within \pm 7 days of the conflict). Periods of at least $10 \mathrm{~min}$ during which neither opponent was involved in another conflict were selected, a posteriori, as MC observations, and used as baseline data for comparison with the PC (see below).

\section{Data Analysis}

We analysed data from a total of 2146 PC-MC pairs (1121 for FS1, 1025 for FS2). According to the PC-MC method, a PC-MC pair was designated as 'attracted' if opponents affiliated earlier or only in the PC than in the MC, as 'dispersed' if the affiliation occurred earlier or only in the MC, and as 'neutral' if it occurred at the same time in both or in neither the PC nor the MC. In our analyses, attracted dyads indicated the presence of reconciliation while dispersed and neutral dyads indicated the absence of reconciliation. For each subject, we compared the number of attracted, dispersed and neutral interactions, calculating an individual's corrected conciliatory tendency (CCT) as follows: $100 \times(($ attracted-dispersed $) /$ all $)$ (Veenema, Das, \& Aureli, 1994). As described, in our statistical models, the occurrence of reconciliation accounted for differences between PC and MC observations and each subject's CCT included all of the PC-MC pairs in which s/he was a part. We analyse individual variation from multiple angles, but individual data were treated separately (i.e. never pooled into larger aggregates).

Generalized multilevel models (GMMs) were conducted in Stata (version 11.2) to test for consistent individual differences in reconciliation (Gelman \& Hill, 2006; Rabe-Hesketh \& Skrondal, 2008) while controlling for the relation between reconciliation and various fixed effects (see Table 1 and below for details on model specification). By allowing the intercept of the statistical models to vary by individual chimpanzee (i.e. as a random effect), we can test whether repeated observations of the same subjects over time show greater stability than would be expected by chance. Notably, we can simultaneously account for the influences of various aspects of the social context (i.e. as fixed effects), making such models a valuable tool for quantifying stable individual differences.

Our first model (Model 1) incorporated a crossed random effects structure (Baayen, Davidson, \& Bates, 2008) with a binary outcome $(0 / 1$ if reconciliation did not/did occur), using a binomial error distribution and logit link function. The data were structured by conflict (i.e. one line of data per conflict) to enable us to control for the fixed effects of conflict (number of participants, intensity), dyad (sex class, age class, kinship, dominance, affiliation level) and group (FS1 or FS2, group size) characteristics. Conflict opponents were entered as crossed random effects. Kinship was restricted to matrilineal relationships, and only (grand)-mother-offspring and
Table 1

Description of variables used in GMMs in Models 1 and 2

\begin{tabular}{|c|c|c|}
\hline Model & Variable & Description \\
\hline \multicolumn{3}{|c|}{ Outcome: reconciliation } \\
\hline 1 & Binary & Occurrence of reconciliation $(0=$ no, $1=$ yes $)$ \\
\hline 2 & Count & $\begin{array}{l}\text { Subject no. of attracted-dispersed pairs } \\
\text { (per year) }\end{array}$ \\
\hline \multicolumn{3}{|c|}{ Random effect: individual } \\
\hline 1 & Opponent $\times$ Opponent & Crossed random effects structure \\
\hline 2 & Subject & Regular random effect structure \\
\hline \multicolumn{3}{|c|}{ Fixed effects } \\
\hline 1 & Participants & Conflict no. of participants \\
\hline 1 & Intensity* & $\begin{array}{l}\text { Conflict intensity }(0=\text { nonphysical aggression } \dagger \text {, } \\
1=\text { physical aggression })\end{array}$ \\
\hline 1 & Kinship* & Dyad kinship $(0=$ not kin, $1=$ kin $)$ \\
\hline 1 & Dominance* & Dyad dominance $(0=$ unequal, $1=$ equal $)$ \\
\hline 1 & Affiliation* & Dyad affiliation $(0=$ not strong, $1=$ strong $)$ \\
\hline 1 & Sex class & $\begin{array}{l}\text { Dyad sex class (all-male, mixed-sex } \ddagger \text {, } \\
\text { all-female) }\end{array}$ \\
\hline 1 & Age class & $\begin{array}{l}\text { Dyad age class (all-adult, mixed-age }+ \text {, } \\
\text { all-adolescent) }\end{array}$ \\
\hline 1,2 & Group & Social group $(0=F S 1,1=F S 2)$ \\
\hline 1,2 & Group size & Social group size \\
\hline 2 & Sex & Subject sex $(0=$ male, $1=$ female $)$ \\
\hline 2 & Age & Subject age class $(0=$ adolescent, $1=$ adult $)$ \\
\hline 2 & Conflicts & Subject no. of conflicts (per year) \\
\hline
\end{tabular}

maternal siblings were considered related. Dominance was based on nonagonistic approach/retreat interactions and the direction of submissive signals. Affiliation level was calculated with a combined measure of four state behaviours (contact sitting, sitting within arm's reach, grooming and mutual grooming) collected during scans, using the quartile points of dyadic scores for each focal individual. Only dyads with scores higher than the top quartile were considered to have a strong affiliative relationship. Dyadic values for dominance and affiliation were calculated for each year independently. When we found an effect of a three-level factor (i.e. sex class or age class) on the occurrence of reconciliation, we ran multiple comparisons between the groups to determine their relative effects in Model 1.

A second model (Model 2) sought to further examine the stability of individual differences by collapsing the data for a count of each subject's reconciliations and conflicts by observation year (i.e. one line of data per individual per year). Because of non-normally distributed annual CCT values (such transformation problems, in our case resulting from a preponderance of years when CCTs equalled zero, are well known for count data with small mean frequencies), we modelled a reconciliation count outcome (the number of attracted-dispersed pairs that a subject had in a given year), controlling for the number of conflicts (i.e. total pairs) that a subject had in that year (entered as a fixed effect) to approximate an individual's tendency to reconcile during that time (Gelman \& Hill, 2006; Rabe-Hesketh \& Skrondal, 2008). A generalized multilevel model with a Poisson error distribution and logit link function was performed, with subject entered as a random effect. Additionally, subject sex and age, as well as group characteristics (social group and group size) were entered as fixed factors (Table 1). Overall, in Model 2, in which we extracted information concerning the interaction for each subject, individual subjects formed the unit of analysis, whereas in Model 1, in which each conflict was considered independently, the opponents therein formed the unit of analysis.

A third set of analyses tested predictions regarding individual CCT and three measures of social switching behaviour. The first, 
social behaviour switches, equals the number of different behaviours that a subject initiated towards another individual over the observation session. All social (i.e. affiliative and agonistic) behaviours were taken into account. An event was also counted as distinct if the subject engaged in the same behaviour but with a different individual. For instance, if 'A grooms B' was followed by 'A grooms $C$ ', the total number of events was two. The second index, social partner switches, equals the number of different individuals towards which a subject directed any behaviour over the observation session. In this case, the number of interactions with each individual was not taken into account. Both indices are expressed as rates per hour and were calculated for each year independently. Finally, an animal's latency to reconcile was calculated as the number of seconds that took place between the end of the conflict and the onset of reconciliation, averaged for each observation year, and then log transformed for normality. We used the two frequency indices as estimations of the overall rate at which individuals switched between different social states, and latency as an indicator of how quickly they did so. Beyond testing our predictions by entering each variable into Model 2 as an additional fixed effect, we compared these measures, averaged across all observations, directly to an individual's mean CCT by collapsing the data by subject (i.e. one line of data per individual). The latter analyses were conducted via separate multiple linear regressions for each variable, entering subject CCT (normally distributed upon collapsing) as the outcome and controlling for subject group, sex and age at the conclusion of the study period.

\section{RESULTS}

\section{Individual Differences}

The mean \pm SD CCT of all 31 individual subjects was $16.3 \pm 7.0 \%$. We found substantial individual variation, such that subject CCTs ranged from $6.5 \%$ to $32.9 \%$ (Fig. 1). Testing this variation, Model 1 revealed a significant crossed random effect of opponents (likelihood ratio test, LRT: 27.47, $P<0.0001$ ). That is, individuals differed reliably in their level of reconciliation while controlling for a variety
Table 2

Results of Model 1

\begin{tabular}{|c|c|c|c|c|c|}
\hline Variable & $\beta$ & SE & $\mathrm{Cl}_{95}$ & Test statistic & $P$ \\
\hline Random effect & & & & $\chi^{2}$ & \\
\hline Opponent 1 & 0.447 & 0.104 & $0.283-0.707$ & 27.47 & 0.000 \\
\hline Opponent 2 & 0.403 & 0.102 & $0.245-0.662$ & 21.47 & 0.000 \\
\hline Fixed effects & & & & $Z$ & \\
\hline Participants & 0.001 & 0.094 & $-0.184-0.186$ & 0.01 & 0.992 \\
\hline Intensity & 0.296 & 0.136 & $0.029-0.563$ & 2.18 & 0.030 \\
\hline Kinship & -0.014 & 0.412 & $-0.820-0.793$ & -0.03 & 0.974 \\
\hline Dominance & -0.305 & 0.392 & $-1.073-0.463$ & -0.78 & 0.437 \\
\hline Affiliation & 0.619 & 0.141 & $0.342-0.897$ & 4.38 & 0.000 \\
\hline \multicolumn{6}{|l|}{ Sex class } \\
\hline All-male & 0.208 & 0.215 & $-0.214-0.630$ & 0.97 & 0.334 \\
\hline All-female & 0.647 & 0.201 & $0.253-1.041$ & 3.22 & 0.001 \\
\hline \multicolumn{6}{|l|}{ Age class } \\
\hline All-adult & 0.718 & 0.166 & $0.392-1.043$ & 4.32 & 0.000 \\
\hline All-adolescent & 1.357 & 0.644 & $0.095-2.619$ & 2.11 & 0.035 \\
\hline Group & 0.041 & 0.268 & $-0.484-0.566$ & 0.15 & 0.878 \\
\hline Group size & 0.003 & 0.075 & $-0.144-0.151$ & 0.04 & 0.968 \\
\hline
\end{tabular}

Conflict opponents were crossed (random effects) to model the presence/absence of reconciliation (outcome) controlling for conflict, opponents' relationship and group characteristics (fixed effects).

Significant $P$ values are shown in bold.

of other factors shown by previous research to affect this behaviour (Table 2). According to Model 1 results, between-individual heterogeneity was relatively high for both opponents, such that the variances for both intercepts were large relative to their standard errors.

Opponent affiliation was also a predictor of reconciliation, indicating that strongly affiliated dyads reconciled significantly more than dyads with weaker affiliation levels. Furthermore, allfemale dyads reconciled significantly more than mixed-sex dyads (showing a similar trend when compared to all-male dyads; $\beta=0.43, P=0.165$ ), and all-adult and all-adolescent dyads reconciled significantly more than mixed-age dyads (there were no significant differences between all-adult and all-adolescent dyads; $\beta=0.64, \quad P=0.332$ ). Additionally, conflicts involving physical

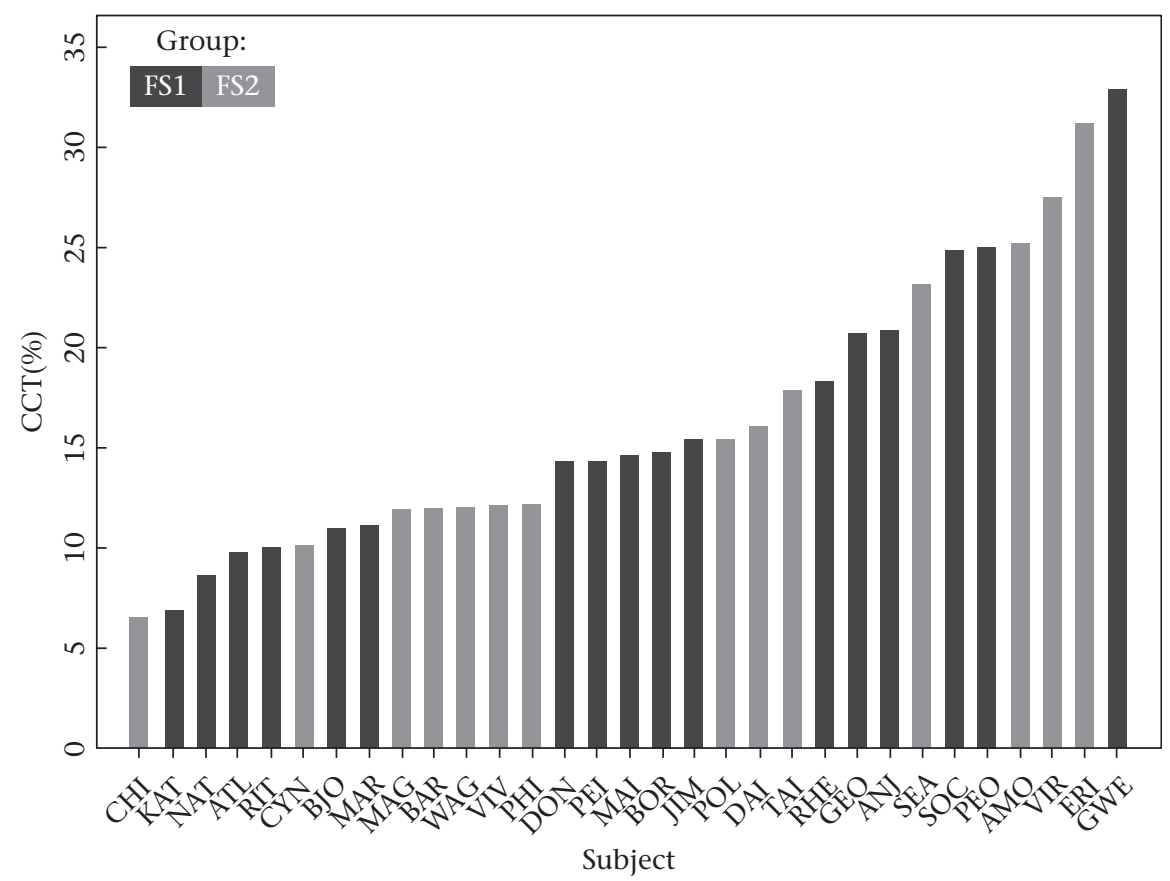

Figure 1. Mean corrected conciliatory tendency (CCT) per subject. 
aggression were reconciled significantly more than those involving nonphysical aggression. Neither the number of conflict participants nor the number of available social partners (i.e. social group size) significantly predicted reconciliation. We found no significant between-group differences, nor influence of kinship or dominance, on the occurrence of reconciliation.

After uncoupling the data for each subject per observation year, the results of Model 2 demonstrated a significant random effect of subject (LRT: 22.56, $P<0.0001$ ), indicating that even when the data were structured by year, individuals were highly stable in their reconciliation tendencies (Table 3). Importantly, this result is reported controlling for the number of conflicts that a subject encountered in a given year, which, unsurprisingly, positively predicted the number of reconciliations he or she had. Consistent with Model 1 results, we found no significant effect of group or group size on subject reconciliations. We also found no significant differences depending on subject sex or age.

\section{Social Switching Behaviour}

Associations were first determined between an individual's mean CCT and his or her average rate of social behaviour switching (mean \pm SD: $4.59 \pm 2.54$ behaviour switches/h), social partner switching (2.84 \pm 2.32 partner switches/h) and overall latency to reconcile $(155.40 \pm 60.85 \mathrm{~s})$. We found a significant positive relation between individual CCT and social behaviour switching ( $\beta=1.24, P=0.027$ ), indicating that subjects who reconciled more tended to switch between different social behaviours at a higher rate (Fig. 2a). We also found a significant positive relation between individual CCT and social partner switching ( $\beta=2.22, P=0.037)$, such that subjects who reconciled more tended to switch between different social partners at a higher rate (Fig. 2b). Furthermore, there was a significant negative association between CCT and average latency to reconcile $(\beta=-5.15, P=0.023)$, indicating that subjects who reconciled more did so more quickly (Fig. 2c). Notably, all three relations were also significant when entered as separate fixed effects into Model 2 (social behaviour switches: $\beta=0.12$, $P<0.001$; social partner switches: $\beta=0.21, P<0.001$; latency to reconcile; $\beta=-0.10, P=0.042$ ), demonstrating their stability over time.

\section{DISCUSSION}

Both Models 1 and 2 support our key hypothesis that chimpanzees exhibit stable individual variation in conciliatory tendency. Whereas Model 1 (structured by conflict) allowed us to control for characteristics of the opponents' relationship, Model 2 (structured by subject) allowed us to control for individual characteristics. We found that, after statistically accounting for these and other

Table 3

Results of Model 2

\begin{tabular}{|c|c|c|c|c|c|}
\hline Variable & $\beta$ & SE & $\mathrm{Cl}_{95}$ & Test statistic & $P$ \\
\hline Random effect & & & & $\chi^{2}$ & \\
\hline Subject & 0.365 & 0.081 & $0.237-0.562$ & 22.56 & 0.000 \\
\hline Fixed effects & & & & $Z$ & \\
\hline Group & 0.175 & 0.175 & $-0.167-0.517$ & 1.00 & 0.316 \\
\hline Group size & -0.054 & 0.061 & $-0.174-0.065$ & -0.89 & 0.374 \\
\hline Sex & -0.257 & 0.198 & $-0.645-0.131$ & -1.30 & 0.194 \\
\hline Age & 0.052 & 0.160 & $-0.261-0.366$ & 0.33 & 0.744 \\
\hline Conflicts & 0.024 & 0.003 & $0.019-0.030$ & 8.34 & 0.000 \\
\hline
\end{tabular}

Subject was entered as a random effect to model its annual reconciliation total (outcome) controlling for its annual conflict total, sex and age class in addition to group characteristics (fixed effects).

Significant $P$ values are shown in bold.
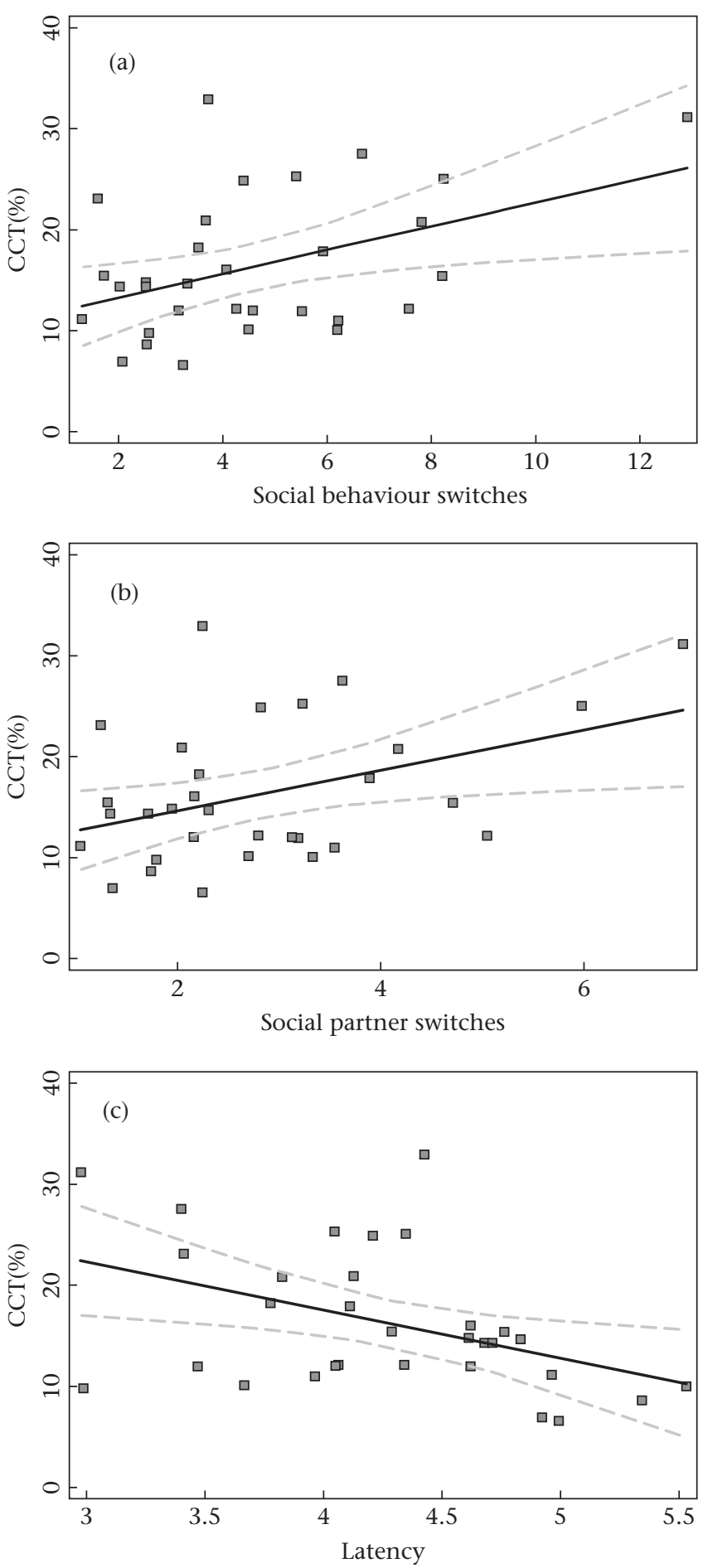

Figure 2. Relation between subject mean corrected conciliatory tendency (CCT) and average (a) social behaviour switches, (b) social partner switches, (c) latency to reconcile (note that the $X$ axis is log transformed). The solid lines are trend lines and the dashed lines denote $95 \%$ confidence intervals.

potential variables, opponents still exhibited stable individual differences in reconciliation (Model 1), and subject CCTs were consistent from one observation year to the next (Model 2). Accordingly, these models revealed individual variation as an important predictor of postconflict behaviour, above and beyond associations established in previous studies.

The affiliation level between opponents was also a predictor of reconciliation. Although this general pattern is consistent with the 
VRH and previous findings in chimpanzees (e.g. Watts, 2006), other results are less clear. Given the value of chimpanzee male alliances, one might expect reconciliation to be highest in all-male dyads, as indeed reported by de Waal (1986), although evidence for this pattern is mixed (reviewed in Watts, 2006). That all-female dyads reconciled more than other pairs (although the difference only reached statistical significance when compared to mixed-sex dyads) could reflect the unusually strong female bonds in the Yerkes groups (Preuschoft et al., 2002), further promoted by having over twice as many female than male subjects. Although past research has typically investigated dyad sex class rather than age class differences, our result demonstrating higher reconciliation among similarly aged social partners may be indicative of compatibility, an additional component of relationship quality (Cords \& Aureli, 2000). Our further finding that conflicts with physical aggression were reconciled more often than those with no physical aggression follows inconclusive evidence in chimpanzees (cf. Koski, Koops, \& Sterck, 2007; Kutsukake \& Castles, 2004) suggesting that it would be useful for future research to explore potential interaction effects (e.g. Koski, de Vries, van den Tweel, \& Sterck, 2007).

More central to the aims of our research, we also found a relation between individual differences in CCT and three separate measures of social switching behaviour. We confirmed that subjects with higher CCTs had higher average rates of social behaviour switching and partner switching and lower mean latencies to reconcile. All three describe locomotion motivation, a more general tendency to initiate, and initiate quickly, movement from state to state (Higgins et al., 2003; Kruglanski et al., 2000). Because reconciliation itself constitutes a motivational shift from one state to another, locomotion motivation was a particularly appropriate general construct for addressing this variation. Our findings suggest that stable individual differences in reconciliation may relate to an underlying motivation to switch between different social states. It is worth noting that an individual's motivation to reconcile (as for other social phenomena) may be difficult to measure, as both partners must be motivated in order for the interaction to occur. While a measure of the motivation to reconcile would ideally include unsuccessful reconciliation 'attempts' (i.e. when individuals attempted to reconcile but their partners did not reciprocate), we are aware of no studies to date that have collected such a measure. In this sense, conciliatory tendency serves as a proxy for the motivation to reconcile. Given this conservative estimate, we still found compelling support for our predictions. We encourage future work to include such unsuccessful efforts to interact with social partners (not only when studying reconciliation, but other social behaviours, e.g. grooming) for a better evaluation of social motivation. Along with the results presented here, such studies can reveal the potential utility of motivational frameworks in exploring the underpinnings of various tendencies and highlight novel interpretations of consistent individual differences in animal behaviour. Beyond advancing a motivational approach to behaviour, however, we hope our study serves as a catalyst for determining other predictors of stable individual differences in reconciliation.

As a social behaviour that exhibits considerable individual consistency across both time and context, reconciliation warrants integration with the animal personality research. For example, sociability, generally defined as the tendency to tolerate and seek interactions with conspecifics, is a relevant personality dimension to postconflict behaviour. Koski's (2011) sociability factor in captive chimpanzees consisted of behaviours important in the formation and maintenance of social relationships (e.g. grooming and seeking/accepting social proximity). Nevertheless, additional factors (labelled positive affect and equitability) comprised other sociopositive behaviours. Accordingly, in primates and other socially complex species, sociability is not unidimensional but likely encompasses many different traits (Koski, 2011). In this regard, understanding how suites of traits correlate as behavioural syndromes (Sih, Bell, \& Johnson, 2004) may benefit from the incorporation of additional aspects of an individual's sociality, namely its conciliatory tendency.

Beyond establishing the stability of individual differences, the role of individual plasticity in conflict and postconflict phenomena provokes further inquiry. More recent emphases in personality research have been placed on phenotypic plasticity, noting that individuals differ not only in their average level of behaviour, but also in their responsiveness to environmental variation (i.e. 'behavioural reaction norms'; Dingemanse, Kazem, Réale, \& Wright, 2010), particularly in the social realm (Bergmüller \& Taborsky, 2010; Réale \& Dingemanse, 2010). If social switching behaviour is suggestive of such social behavioural flexibility (or 'social sensitivity': Sih, 2013; Sih \& Bell, 2008) more broadly, we can generate hypotheses about whether individuals with higher conciliatory tendencies would exhibit more plasticity in reconciliation. Investigating the shapes of behavioural reaction norms as a function of various social contexts (e.g. across different social partners) therefore represents an important next step. With respect to our earlier point, one could investigate whether an individual's motivation to reconcile is directed preferentially at those partners who are most likely to reciprocate. If such regulated expression optimizes an individual's relationships, conciliatory behaviour would therefore represent a novel domain in which to evaluate social competence (Taborsky \& Oliveira, 2012). How both the consistency and plasticity of reconciliation reflect and influence other aspects of sociality, such as the nature of an individual's social bonds or network position, are additional considerations for future research.

\section{Conclusions}

Reconciliation is conceptually rooted in a relational discourse, notably that of the VRH. We have established that beyond relationship value, stable individual differences represent an additional and potentially meaningful source of variation in conciliatory tendency. Despite conflict being a pervasive and potentially disruptive element of sociality in primates and other gregarious species, postconflict behaviour has not been a focus of animal personality research. Although often less intuitive to approach the study of sociality from the individual level of analysis, individual differences influence how social processes themselves unfold. To the extent that those differences in part drive the formation and maintenance of social relationships, they have more ultimate consequences. In particular, insofar as an individual's conciliatory tendency shapes or reinforces the strength and stability of its social bonds, it can also impact its fitness. Although this remains an open question, our findings suggest a relatively unexplored area of research warranting further study.

\section{Acknowledgments}

We are grateful to Michael Seres for the behavioural data collection of this study. We also thank the animal care and veterinary staff at the Yerkes National Primate Research Center (YNPRC) for maintaining the health and wellbeing of the chimpanzees. This work was supported by Emory's College of Arts and Sciences as well as the Base Grant of the National Institutes of Health to the YNPRC (RR-00165; currently supported by the Office of Research Infrastructure Programs/ODP51OD11132) and funding by the Living Links Center. We thank Marina Cords for helpful conversations and feedback on this research, and two anonymous referees whose insightful and constructive comments improved the quality of this manuscript. 


\section{References}

Aureli, F., Cords, M., \& van Schaik, C. P. (2002). Conflict resolution following aggression in gregarious animals: a predictive framework. Animal Behaviour, 64, $325-343$.

Baayen, R. H., Davidson, D. J., \& Bates, D. M. (2008). Mixed-effects modeling with crossed random effects for subjects and items. Journal of Memory and Language, 59, 390-412.

Bell, A. M., Hankison, S. J., \& Laskowski, K. L. (2009). The repeatability of behaviour: a meta-analysis. Animal Behaviour, 77, 771-783.

Bergmüller, R., \& Taborsky, M. (2010). Animal personality due to social niche specialization. Trends in Ecology E' Evolution, 25, 504-511.

Cools, A. K. A., Van Hout, A. J. M., \& Nelissen, M. H. J. (2008). Canine reconciliation and third-party-initiated postconflict affiliation: do peacemaking social mechanisms in dogs rival those of higher primates? Ethology, 114, 53-63.

Cordoni, G., \& Palagi, E. (2008). Reconciliation in wolves (Canis lupus): new evidence for a comparative perspective. Ethology, 114, 298-308.

Cords, M., \& Aureli, F. (2000). Reconciliation and relationship qualities. In F. Aureli, \& F. B. M. de Waal (Eds.), Natural conflict resolution (pp. 177-198). Berkeley, CA, U.S.A.: University of California Press.

Cords, M., \& Thurnheer, S. (1993). Reconciliation with valuable partners by longtailed macaques. Ethology, 93, 315-325.

Dingemanse, N. J., Kazem, A. J. N., Réale, D., \& Wright, J. (2010). Behavioural reaction norms: animal personality meets individual plasticity. Trends in Ecology \& Evolution, 25, 81-89.

Dingemanse, N. J., \& Réale, D. (2005). Natural selection and animal personality Behaviour, 142, 1165-1190.

Franks, B., Higgins, E. T., \& Champagne, F. A. (2012). Evidence for individual differences in regulatory focus in rats, Rattus norvegicus. Journal of Comparative Psychology, 126, 347-354.

Franks, B., Reiss, D., Cole, P., Friedrich, V., Thompson, N., \& Higgins, E. T. (2013). Predicting how individuals approach enrichment: regulatory focus in cottontop tamarins (Sanguinus oedipus). Zoo Biology, 32, 1-9.

Fraser, O. N., \& Bugnyar, T. (2011). Ravens reconcile after aggressive conflicts with valuable partners. PLoS One, 6, e18118.

Freeman, H. D., \& Gosling, S. D. (2010). Personality in nonhuman primates: a review and evaluation of past research. American Journal of Primatology, 72, 653-671.

Gelman, A., \& Hill, J. (2006). Data analysis using regression and multilevel/hierarchica. models. Cambridge, U.K.: Cambridge University Press.

Higgins, E. T. (1997). Beyond pleasure and pain. American Psychologist, 52, 1280 1300.

Higgins, E. T. (2012). Beyond pleasure and pain: How motivation works. New York, NY, U.S.A.: Brunner-Routledge.

Higgins, E. T., Kruglanski, A. W., \& Pierro, A. (2003). Regulatory mode: locomotion and assessment as distinct orientations. In M. P. Zanna (Ed.), Advances in experimental social psychology (Vol. 35); (pp. 293-344). New York, NY, U.S.A.: Academic Press.

van Hooff, J. A. R. A. M. (1974). A structural analysis of the social behaviour of a semi-captive group of chimpanzees. In M. von Cranach, \& I. Vine (Eds.), Social communication and movement (pp. 75-162). London, U.K.: Academic Press.

Kappeler, P. M., \& van Schaik, C. P. (1992). Methodological and evolutionary aspects of reconciliation among primates. Ethology, 92, 51-69.

Koski, S. E. (2011). Social personality traits in chimpanzees: temporal stability and structure of behaviourally assessed personality traits in three captive populations. Behavioral Ecology and Sociobiology, 65, 2161-2174.

Koski, S. E., Koops, K., \& Sterck, E. H. M. (2007). Reconciliation, relationship quality, and postconflict anxiety: testing the integrated hypothesis in captive chimpanzees. American Journal of Primatology, 69, 158-172.

Koski, S. E., de Vries, H., van den Tweel, S. W., \& Sterck, E. H. M. (2007). What to do after a fight? The determinants and inter-dependency of post-conflict interactions in chimpanzees. Behaviour, 144, 529-555.

Kruglanski, A. W., Thompson, E. P., Higgins, E. T., Atash, M. N., Pierro, A., Shah, J. Y., et al. (2000). To 'do the right thing' or to 'just do it': locomotion and assessment as distinct self-regulatory imperatives. Journal of Personality and Social Psychology, 79, 793-815.

Kutsukake, N., \& Castles, D. L. (2004). Reconciliation and post-conflict third-party affiliation among wild chimpanzees in the Mahale Mountains, Tanzania. Primates, 45, 157-165.

Leary, M. R., \& Hoyle, R. H. (Eds.). (2009). Handbook of individual differences in social behavior. New York, NY, U.S.A.: Guilford Press.
McCullough, M. E., Luna, L. R., Berry, J. W., Tabak, B. A., \& Bono, G. (2010). On the form and function of forgiving: modeling the time-forgiveness relationship and testing the valuable relationships hypothesis. Emotion, 10, 358-376.

McCullough, M. E., Worthington, E. L. J., \& Rachal, K. C. (1997). Interpersonal forgiving in close relationships. Journal of Personality and Social Psychology, 73, $321-336$.

Preuschoft, S., Wang, X., Aureli, F., \& de Waal, F. B. M. (2002). Reconciliation in captive chimpanzees: a reevaluation with controlled methods. International Journal of Primatology, 23, 29-50.

Rabe-Hesketh, S., \& Skrondal, A. (2008). Multilevel and longitudinal modeling using Stata. College Station, TX, U.S.A.: Stata Press.

Réale, D., \& Dingemanse, N. J. (2010). Personality and individual social specialization. In T. Székely, A. J. Moore, \& J. Komdeur (Eds.), Social behaviour: Genes, ecology and evolution (pp. 417-441). Cambridge, U.K.: Cambridge University Press.

Romero, T., Castellanos, M. A., \& de Waal, F. B. M. (2011). Post-conflict affiliation by chimpanzees with aggressors: other-oriented versus selfish political strategy. PLoS One, 6, e22173.

Romero, T., \& de Waal, F. B. M. (2010). Chimpanzee (Pan troglodytes) consolation: third-party identity as a window on possible function. Journal of Comparative Psychology, 124, 278-286.

Schino, G. (2000). Beyond the primates: expanding the reconciliation horizon. In F. Aureli, \& F. B. M. de Waal (Eds.), Natural conflict resolution (pp. 225-242). Berkeley, CA, U.S.A.: University of California Press.

Seyfarth, R. M., Silk, J. B., \& Cheney, D. L. (2012). Variation in personality and fitness in wild female baboons. Proceedings of the National Academy of Sciences of the United States of America, 109, 1-6.

Sih, A. (2013). Frontiers on the interface between behavioral syndromes and social behavioral ecology. In C. Carere, \& D. Maestripieri (Eds.), Animal personalities: Behavior, physiology, and evolution (pp. 221-251). Chicago, IL, U.S.A.: University of Chicago Press.

Sih, A., \& Bell, A. M. (2008). Insights for behavioral ecology from behavioral syndromes. Advances in the Study of Behavior, 38, 227-281.

Sih, A., Bell, A., \& Johnson, J. C. (2004). Behavioral syndromes: an ecological and evolutionary overview. Trends in Ecology E Evolution, 19, 372-378.

Sih, A., Bell, A. M., Johnson, J. C., \& Ziemba, R. E. (2004). Behavioral syndromes: an integrative overview. Quarterly Review of Biology, 79, 241-277.

Silk, J. B., Beehner, J. C., Bergman, T. J., Crockford, C., Engh, A. L., Moscovice, L. R., et al. (2010). Strong and consistent social bonds enhance the longevity of female baboons. Current Biology, 20, 1359-1361.

Taborsky, B., \& Oliveira, R. F. (2012). Social competence: an evolutionary approach. Trends in Ecology \& Evolution, 27, 679-688.

Uher, J., Asendorpf, J. B., \& Call, J. (2008). Personality in the behaviour of great apes: temporal stability, cross-situational consistency and coherence in response. Animal Behaviour, 75, 99-112.

Veenema, H. C., Das, M., \& Aureli, F. (1994). Methodological improvements for the study of reconciliation. Behavioural Processes, 31, 29-38.

de Waal, F. B. M. (1986). The integration of dominance and social bonding in primates. Quarterly Review of Biology, 61, 459-479.

de Waal, F. B. M. (1989). Food sharing and reciprocal obligations among chimpanzees. Journal of Human Evolution, 18, 433-459.

de Waal, F. B. M. (2000). Primates: a natural heritage of conflict resolution. Science, 289, 586-590

de Waal, F. B. M., \& Aureli, F. (1997). Conflict resolution and distress alleviation in monkeys and apes. In C. S. Carter, B. Kirkpatric, \& I. Lenderhendler (Eds.), The integrative neurobiology of affiliation (Vol. 807); (pp. 317-328). New York, NY, U.S.A.: Annals of the New York Academy of Sciences.

de Waal, F. B. M., \& van Hooff, J. A. R. A. M. (1981). Side-directed communication and agonistic interactions in chimpanzees. Behaviour, 77, 164-198.

de Waal, F. B. M., \& van Roosmalen, A. (1979). Reconciliation and consolation among chimpanzees. Behavioral Ecology and Sociobiology, 5, 55-66.

de Waal, F. B. M., \& Yoshihara, D. (1983). Reconciliation and redirected affection in rhesus monkeys. Behaviour, 85, 224-241.

Watts, D. P. (2006). Conflict resolution in chimpanzees and the valuablerelationships hypothesis. International Journal of Primatology, 27, 1337-1364.

Webb, C. E. (2011). Motivations for reconciliation: Regulatory mode, individual differences, and evolutionary considerations (Master's thesis). New York, NY, U.S.A.: Columbia University.

Wilson, D. S., Clark, A. B., Coleman, K., \& Dearstyne, T. (1994). Shyness and boldness in humans and other animals. Trends in Ecology \& Evolution, 9, 442-446. 